\section{Indian science needs alternative investors}

India needs to look beyond its government and find other investors that can transform the face of science there (Nature 484, 159-160; 2012). The private sector and philanthropic organizations must step in if the country is to realize its huge scientific potential.

India has opened up

its financial markets,

telecommunications and retail to foreign investment - education and science should follow suit. It should provide incentives for foreign universities, funding agencies and multinational corporations to invest in India's education and research, within a regulatory framework under strict oversight. The government could help to promote the economic and social returns on these investments to other interested parties.

India's nouveau riche need to follow the example of US and UK philanthropists and set up research foundations. Together with non-profit organizations, they can invest in high-risk, lowreturn areas of science not usually considered by the private sector.

As a young Indian scientist who aspires to build up a public-health genomics research programme in India, I believe that input from a variety of funding sources will help to drive competition and improve scientific output and accountability.

Siddhartha P. Kar University of Texas, Houston, Texas, USA. siddhartha.p.kar@uth.tmc.edu

\section{Cyprus Institute: it deserves more credit}

Your pessimistic report on the state of the Cyprus Institute in Nicosia (Nature 484, 14; 2012) is based on a selection of distorted negative quotes. As chairman of the institute's trustees, I believe that this view is misleading and damaging to its hard-won scientific reputation in a region with little research history.
The morale of institute staff is low at present, but that is down to repeated delays in state funding rather than to its president's management style. You highlight harsh criticism from Nicholas Papadopoulos, chair of the parliament finance committee, but he has never visited the institute - despite repeated invitations. His comments are at odds with the government's whole-hearted support (see go.nature.com/ fkqphb).

You are incorrect in saying that the institute signed an agreement with the Massachusetts Institute of Technology (MIT) to design a solar-energy plant, which is an initiative funded by the European Union; MIT is one of the partners in the institute's Energy, Environment and Water Research Center, which, among other projects, is in charge of the plant. You should also have mentioned that an audit found no improprieties in the institute's finances.

In our interviews for the story, Jos Lelieveld and I expressed full confidence in the institute and its management, but our views failed to come over in your report. I stressed, among other things, the board and scientific council's overwhelming acknowledgement of the institute's development and successes, and of the credit due to its staff and leadership, particularly its president. Edouard Brézin Laboratory of Theoretical Physics, Ecole Normale Superieure, Paris, France.brezin@lpt.ens.fr

\section{Cyprus Institute: improve oversight}

As a scientist formerly employed by the Cyprus Institute, I believe that it is time for the Cyprus government to bring in new management that will have proper oversight (Nature 484, 14; 2012).

The government auditor's report on the institute's finances was unfortunately published only in Greek. It highlights several irregularities, including a lack of transparency and formal organizational structure.

Allocation of resources has been inadequate and several staff members, including myself, have found the institute a difficult place to do research. In 2010, $13 \%$ of the staff resigned, and $20 \%$ of the remainder left in 2011 — including some senior staff members. This has been bad for research in Cyprus.

Considering the amount of money the government has poured into the institute and the number of researchers on the staff, the institute's scientific output seems low - and some of the publications listed on its website do not carry the institute's affiliation.

An independent committee should be formed to evaluate the institute's research according to international standards.

This would replace its scientific advisory council, which consists mainly of members of its board of trustees and scientists from affiliated institutions.

Emmanouil Lioudakis Cyprus

Physicists Society, Nicosia,

Cyprus.

manolis.lioudakis@gmail.com

\section{A UK tissue bank for breast tumours}

As chairman of the Breast Cancer Campaign Tissue Bank Management Board, I, along with my co-signatories, believe that researchers should have better access to breast-cancer tissue. Christina Curtis and her colleagues, for example, had to approach five tissue banks for the 2,000 samples they used to identify ten distinct types of breast tumour (C. Curtis et al. Nature http://doi.org/hvk; 2012).

Historically, inaccessibility of tissue samples and materials for breast-cancer research has been a major obstacle to translating science into new treatments, with researchers sometimes spending months tracking down suitable samples. A shortage of good-quality tissue with matching clinical data has been another hindrance.

The multicentre UK Breast Cancer Campaign Tissue Bank was opened earlier this year to help solve these problems (see go.nature.com/swbsrj). By offering annotated samples to all breast-cancer researchers in the United Kingdom and Ireland, it will help to speed the translation of findings into benefits for patients.

Alastair M. Thompson on behalf of ten co-signatories ${ }^{*}$, Dundee Cancer Centre, University of, Dundee, UK.sgriffiths@ breastcancercampaign.org ${ }^{\star}$ See go.nature.com $/ x f$ ckko for a full list.

\section{Science sociology began before Kuhn}

David Kaiser marks the 50th anniversary of the publication of Thomas Kuhn's best-selling The Structure of Scientific Revolutions (Nature 484, 164$165 ; 2012)$. It is only fair to point out that many of the same ideas had already been formulated by the Polish microbiologist and philosopher of science Ludwik Fleck in his 1935 study Genesis and Development of a Scientific Fact (translated into English in 1979). Kuhn acknowledged Fleck's contribution in the foreword to the first edition of his book, but this was ignored in the intense debate that followed its publication.

Fleck coined the term 'incommensurability' in 1927, which is still indispensable in discussions on Kuhn and the sociology of scientific knowledge. More on Fleck's theories and his influence on Kuhn's thinking can be found in the Stanford Encyclopedia of Philosophy (see go.nature.com/hpwnvd). Ulrich Lehmann Institute of Pathology, Hanover Medical School, Germany.

lehmann.ulrich@mh-hannover.de 